DOI 10.37882/2223-2982.2020.05.25

\title{
ГЕНЕЗИС ЗАЛОГОВЫХ КАТЕГОРИЙ В ГЕРМАНСКИХ ЯЗЫКАХ
}

\section{GENESIS OF MORTGAGE CATEGORIES IN GERMAN LANGUAGES}

\section{O. Orekhova}

Summary: The article analyzes the origin of collateral categories in Germanic languages (GY); periods of chronological periods of mortgage categories of the German language (AE) as a system of morphological and syntactic mutual relations are considered.

In particular, a description of the typology and opposition in the functioning of collateral verb forms in the Gothic (GothJ) and German languages is presented, an attempt is made to determine the syncretic and hierarchical dependencies, the degree of grammatization and morphologization of the collateral categories of the German language.

Keywords: grammatical category, pledge, asset, passive, media passive, syncretism, hierarchy, grammatization, morphologization.

\author{
Орехова Оксана Евгеньевна \\ К.и.н., дочент, МГИМО МИД РФ \\ frauo@bk.ru
}

Аннотация: В статье осуществлен анализ происхождения залоговых категорий в германских языках (ГЯ); рассмотрены периоды хронологические периоды залоговых категорий немецкого языка (НЯ) как системы морфологических и синтаксических взаимных связей.

В частности, представлено описание типологии и противопоставления В функционировании залоговых глагольных форм в готском (ГотЯ) и немецком языках, осуществлена попытка определения синкретических и иерархических зависимостей, степени грамматикализации и морфологизации залоговых категорий немецкого языка.

Ключевые слова: грамматическая категория, залог, актив, пассив, медиапассив, синкретичность, иерархичность, грамматикализация, морфологизация.

ется действие и процесс [2].

Учитывая это, грамматическая категория не существует в языке изолированно, она входит в систему исторических, морфологических, синтаксических, прагматических и семантических коллизий. Залоговая категория глаголов является противоречивой категорией современного языкознания из-за ее оппозиционности, многоаспектности, полисемантичности.

Исходной категорией является форма актива, которая равноправно существует в системе каждого языка. Противостоит активному состоянию состав морфологически-факультативных форм - пассив, медиум, рефлексив, реципрок, кооператив, каузатив, медиапассив [3].

В языкознании актив и пассив считаются доминантными формами вербальных категорий. В истории лингвистики пассивное состояние традиционно рассматривался в одновременном взаимосвязи и сопоставлении с другими грамматическими формами, прежде всего с действительным состоянием [3].

В нашем исследовании генезиса категории состояния глаголов ГЯ мы опираемся на научные труды таких авторов, как: Л.Р. Зиндер, Т.В. Строева [4]; В.Г. Адмони [5]; М.М. Гухман [6, 7]; С.А. Шубик [8, 9]; Н.С. Жукова [10]; E. Agricola, W. Fleischer [11] и других.

Цель исследования мы видим в изучении происхождения залоговых категорий в ГЯ и представлении периодизации залоговых категорий НЯ как системы морфолого-синтаксических корреляций. 
Во время научного поиска нами были сформулированы следующие задачи:

- описать типологию и оппозиционный характер функционирования залоговых глагольных конструкций ГЯ (на примере ГотЯ и НЯ);

- попытаться определить синкретичные и иерархические зависимости, степень грамматикализации и морфологии залоговых категорий в ГЯ, в частности в НЯ.

\section{Результаты исследования}

Грамматические категории иерархически не статичны. Каждому историческому периоду развития системы речи соответствуют собственные перечень и содержание морфологических категорий, определение взаимоотношений между ними. Чтобы понять взаимосвязь залоговых категорий сегодняшнего НЯ и объяснить их системное положение необходимо рассмотрение глагольной подсистемы НЯ в динамике, то есть с точки зрения историзма, в соответствии с которой нужно постоянно учитывать историческую перспективу как относительно предыдущих периодов, так и направлений дальнейшего развития.

Отправной точкой сравнения современных ГЯ с предыдущими периодами развития является ГотЯ, который единственный из древнегерманских языков сохранился в письменности. По утверждению Н. Жуковой, использование явления синкретизма как показателя зависимости категорий позволяет принять такую иерархию глагольных категорий в ГотЯ: Person - 77\%, Zahl - $62 \%$, Modus - 54 $\%$, Zeit - 44,5 \%, Genera verbi - $30 \%$ [10, 10-15].

По свидетельству Н.С. Жуковой [10], в ГотЯ отсутствовали независимые категории с полностью морфологической выраженностью. При этом залоговая категория находилась в зависимости от иных категорий и представляла собой двухкомпонентное противопоставление «актив vs медиапассив», являвшееся асимметричным, поскольку актив использовался в двух временных формах (презенс и притериум - настоящее и прошедшее) и полной парадигме (индикатив, оптатив, императив), тогда как его оппонент - медиапассив - только в форме презенс (настоящее время) и двух модальных реализациях: индикатив и оптатив. В целом категория состояния ГотЯ находилась в зависимости от категорий лица, числа, времени и наклонения.

Следовательно, в ГотЯ синкретичные формы в категории залога говорят об асимметрии его парадигмы и показывают охватившие его изменения. Таким образом, рассматривая глагольную подсистему мы видим, что периферийное положение залоговой категории в ней говорит об исчезновении этой категории.
Еще М. Гухман [6] отмечала, что, как правило, форма ГотЯ медиапассив использовалась в значении пассивного состояния (презенс и футур): all bagme ni taujandame arken god usmaitada jah in fon galagjada (любое дерево, не дающее спелого доброго плода, срубают и бросают в огонь). В некоторых случаях по этой форме называется деятель: ei hauhjandau fram mannam (чтобы быть славными людьми).

Однако есть и другие случаи, когда форма медиапассива употреблялась в несколько ином значении. Например, от глагола preihan (теснить) медиапассивные формы имели непереходно-обратное значение: ni preihanda jus in uns is preihanda in hairpram iywaraim (не теснитесь в нас, но теснитесь в ваших сердцах); с другим лексическим оттенком: appan jappe preihanda in izwaraizios gaplahtais (но если терпимо, то ради вашей утехи).

Моральное состояние, аффект выражали и формы глаголов ufblesan (превозносить), ingramjan (раздражать), которые встречались исключительно в медиапассиве: friapwa ni aljanop, friapwa ni flauteip, ni ufblesada, ni aiwiskop... ni ingramjada (любовь не завидует, любовь не хвастается, не превозносит, не бесчинствует). Иногда медиапассивные формы изменяли у глагола не столько залоговое, сколько лексическое значение. Так, afwandjan (возвращать, отвлечь, изменить) в медиапассиве получает значение «изменить мнение» $[7,174-180]$.

Следовательно, готский медиапассив генетически связан с медиумом, как следствие он не всегда означал пассивное состояние, однако мог отражать такие медиальные оттенки, как непереходимость, моральнонравственное состояние, состояние аффекта. Совокупность форм медиапассива могла выражать настоящее / будущее времена. Например, употребление будущего времени: saei habaip gibada imma (кто имеет, тому будет отдано).

Ограниченность в ГотЯ временных форм медиапассива обусловила привлечение к системе залоговых противопоставлений группировок глаголов IV класса и конструкций партиципа II переходных глаголов с формами глаголов wisan и wairpan. IV класс слабых глаголов был достаточно ограниченной лексической группой, в которой все глаголы являлись непереходными, большинство из которых опрпделяло состояние, которое не зависит от действий субъекта. Поэтому соотношение признаков (определяющего глагола) с носителем этих признаков (субъектом-подлежащим) были подобны тем значениям, которые выражались в медиапассивной форме.

Особенно ярко эта близость залоговых значений обеих категорий проявляется при сопоставлении глаголов IV класса с медиапассивом переходного глагола, образованным от того же самого корня. Сравним формы глагола 
IV класса usfullnan (осуществляться) и медиапассивные формы глагола usfulljan (исполнять, исполняться):

a) ei usfullnodedi pada gamelido pairh Esaian praufetu (чтобы исполнилось сказанное пророком Исайей);

б) ei faheps meina in izwis sijai jah faheds izwara usfulljaidau (чтобы радость моя находилась в вас, и радость ваша исполнилась) [7, 174-180].

Иногда в одном и том же предложении используются обе грамматические категории как полные грамматические синонимы, которые передают одну и ту же форму оригинала.

Сравним употребление формы третьего лица единственного числа настоящего времени от глагола IV класса gataurnan (прекратиться, уничтожиться, ликвидироваться): friapwa aiw ni gadriusip, ip jappe paraufetja gatairanda jappe razdos gaheiland jappe kunpi gataurnip (любовь никогда не пропадет, даже если пророчества прекратятся, языки умолкнут и знания уничтожатся).

Тем не менее при использовании медиапассивных форм и глаголов IV класса были и значительные отличия: они никогда не использовались в предложении, где обозначался деятель. Например, ei hauhjandau fram mannam (чтобы быть славными людьми), медиапассивная форма не могла быть заменена формой глагола IV класса. В coчетаниях партиципа II здесь и далее с формами глаголов wisan, wairpan носителем залогового значения был партицип; формы служебных глаголов вносили модификации преимущественно видовременного характера. В структурном отношении эти словосочетания представляли собой именное сказуемое: партицип выполнял функцию предикатива и согласовывался в роде, числе и падеже с подлежащим, а формы глаголов wisan, wairpan выполняли функцию связи [7, 174-180].

Сочетание партиципа II с формами настоящего времени wisan употреблялось для обозначения любого состояния или качества, имеющихся в настоящем времени, которые, однако, были результатом преддействия: hausideup patei qipan ist paim airizam (слушайте, что было сказано предками). Медиапассивные формы от таких глаголов не имели значения результата действия и подчеркивали реализацию самого процесса. Конструкции партиципа II с формами претерита глагола wisan (быть) означали состояние, качество, оказывались прошлым временем и также были результатом преддействия: јаһ bundans was eisarnabandjom (был привязан железными цепями).

Вместе с тем это же сочетание могло употребляться для обозначения какого-либо факта, который случился в прошедшем времени (констатирующий прошедшее время): insandips was aggilus (послан был ангел). Употре- бление словосочетания такого типа в функции констатирующего прошедшего времени без результативного оттенка встречалось достаточно редко, поскольку в этом качестве использовалось преимущественно сочетание партиципа II с формами претерита от глагола wairpan (становиться) [7, 174-180].

Конструкции партиципа II с формами настоящего времени от глагола wairpan (становиться) встречались только один раз. Наличие форм медиапассива настоящего времени, форм настоящего времени глаголов IV класса и, наконец, сочетание партиципа II с формами настоящего времени глагола wisan (быть) не оставляло, очевидно, места для употребления подобных конструкций.

И, наоборот, сочетание партиципа II с формами прошедшего времени от глагола wairpan были очень распространены в готских текстах. Эти сочетания использовались исключительно для обозначения факта, который случился в прошлом, то есть в функции констатирующего прошлого времени или претерита пассивного состояния: jah gataihan warp imma (и было ему сообщено) $[7,174-180]$.

Несмотря на разноплановость средств выражения, связанных с пассивным состоянием, мы можем обобщить, что в ГотЯ не существовало единой грамматической парадигмы этого состояния. Многозначность той же самой формы и категории пересекалась с наличием почти синонимичных образований, что раскрывало многоаспектность и оппозиционность их употребления.

Дальнейшее историческое развитие продемонстрировало, что медиапассив, который относился в ГотЯ к периферии системы, целиком отмер уже в древневерхненемецком языке. Приведенное Н. Жуковой процентное соотношение подтверждает это: Zahl - 93 \%, Zeit - 80 $\%$, Person - $73 \%$, Modus - $48 \%$ [10, 10-15].

Э. Агрикола и В. Фляйшер [11], корифеи немецкой классической лингвистики, исследуя становление аналитических вербальных форм, отмечали, что старонемецкий и старосаксонский глаголы имели такие формы: активное состояние, временные формы (презент и претерит), модус (индикатив, конъюнктив и императив), вербальные номинативные конструкции (инфинитив презенс, партицип презенс и партицип претеритум).

Описательные формы пассивного состояния, времен перфекта, плюсквамперфекта и футура развились в только в ранненемецкий период. В старонемецком периоде описательные формы презенса и претерuта nacсива развивались благодаря глаголам wesan и werdan в сочетании с партиципом претеритумом. Формы wesan и werdan развивались параллельно, например: er ist ginoman - er wirdit ginoman — er wird genommen;er was 
ginoman - erward ginoman - erwurde genommen. Описательные формы с werdan существовали лишь отграничено и исключительно для обозначения презенса и претеритума, а описательные конструкции с wesan служили для выражения перфекта и плюсквамперфекта и находились под влиянием латыни, например: er ist ginoman, er was ginoman означали в переводе на современный НЯ er ist genommen worden, er war genommen worden.

В этот период временная форма пассивных конструкций полностью переформатировалась. Активное состояние строилось с помощью перфекта и плюсквамперфекта с группой интранзитивных глаголов и с глаголом wesan. Например, er ist queman, er was queman - er ist gekommen, er war gekommen. Наряду с этим в старонемецком периоде появились описательные конструкции перфекта и плюсквамперфекта с haben и eigan с транзитивними и интранзитивними глаголами, например: er haben gizeigot — er hat gezeigt; wir eigun gisprochan — wir haben gesprochen [11, 129-130].

Современные исследования также доказывают, что в древневерхненемецком периоде отсутствовала категория залога, поскольку не был сформирован пассив как оппозиционный компонент актива, что обусловливалось слабым развитием соответственных синтаксических средств, нужных для оформления категории залога как морфолого-синтаксической.

Нередко встречавшиеся в письменных памятниках конструкции c wesan являются собой преимущественно предикативным использованием партиципа в значении залога как результата какого-то действия. Даже когда эти конструкции означали действие, направленное на субъект, в любом случае они не оппонировали активу как представители одного противопоставления, поскольку пока что не были морфологизированы, т.е. пассив еще находился на этапе становления [10, 10-15].

В средневерхненемецком периоде завершается грамматикализация пассива, что, одновременно, было связано с развитием в данный период истории синтаксических средств, принимавших участие в организации отображения категории залога, а именно: двухкомпонентность предложения (обязательное отображение субъекта), установившийся словопорядок (зафиксирована позиция сказуемого), наличие в пассивном предложении предлогов, необходимых для представления агенса.

Следовательно, в средневерхненемецком уже наличествует противопоставление «актив vs пассив». В соответствии с классическим подходом считалось, что в указанный период пассивное состояние имело совершенную временную парадигму [3].
Однако Н. Жукова полагает, что в средневерхненемецком периоде в пассивном состоянии отсутствовали аналитические формы перфекта, плюсквамперфекта и конъюнктива, поэтому морфологическая представленность залоговой категории составляла лишь 33\% (Zahl - 93\%, Zeit - 54\%, Person - 61\%, Genera verbi - 33\%, Modus - 18\%) [10, 10-15].

В средневерхненемецком периоде НЯ формируются пассивные формы перфекта и плюсквамперфекта, однако было бы неоправданным рассматривать данные конструкции как совершенные грамматикализированные. Удаленность этой категории от ядра глагольной системы, а также асимметричный характер ее парадигмы подтверждают верность такого подхода, поскольку говорят о неразвитости категории залога, что свидетельствует о ней, как находящейся в процессе становления.

Окончательная грамматикализация перфекта и плюсквамперфекта пассивного состояния, по мнению Н. Жуковой, заканчивается в ранненововерхненемецком периоде одновременно с таким процентным развитием соответствующих синтаксических средств: Genera verbi - 100\%, Modus - 100\%, Zahl - 93\%, Person 70\%, Zeit - 67\%, Redeart - 58\%, Willenaufierung - 7\% [10, 10-15].

Иерархическое расположение глагольных категорий в ранненововерхненемецкий период указывает на то, что пассивное состояние имеет полную парадигму, что говорит об окончании процесса формирования категории залога, парадигма которой стала симметричной, то есть в ней отсутствуют синкретичные формы и, как следствие, она характеризуется полноценной морфологической выраженностью. В ранненововерхненемецкий период категория залога занимает ведущее место в системе НЯ, сохраняя его да настоящего времени.

Именно поэтому изучение грамматической системы НЯ в разные периоды его развития показало, что генезис категории залога происходил одновременно с развитием синтаксической структуры предложения, поскольку категория залога изначально составлялась как синтаксически-морфологическая категория. Синтаксическая особенность исследуемого противопоставления состоит в том, что актив и пассив представлены и выражены не только в формах глаголов, но и в отношениях глагола-сказуемого с подлежащим и дополнением. Иначе говоря, можно говорить об про активной и пассивной конструкции, активных и пассивных оборотах, где глагол является лишь одним из участников залоговых отношений [12]. 


\section{Зак^ючение}

Учитывая вышесказанное, можно сделать следующие вывод.

Процесс развития залоговых категорий в НЯ имеет закономерную и обусловленную определенными объективными причинами периодизацию, а именно:

1. синкретический период (внутриуровневая и межуровневая зависимость залоговых категорий друг от друга, их относительная размытость и неоднозначность);

2. иерархический период (процесс перестройки категорий залога и изменение морфологического статуса иерархических зависимостей, их дальнейшая детализация);

3. период грамматикализации (процесс получения грамматического статуса, развитие синтаксических средств связи между категориями, организация общего плана выражения категориального залога);

4. период морфологизации (окончательный отказ от синкретичных отношений, выделение залоговых категорий, совершенствование средств их выражения);

5. морфолого-синтаксический период (параллельное системное соотношение и/или оппозиция синтаксической и морфологической сторон).

В дальнейшем мы считаем целесообразным продолжить детальное исследование периодизации и типологии категории залога, залогового поля; осуществление многоаспектного исторического и сравнительно-типологического исследования категорий залога в германских языках, а именно: в немецком, готском, английском, исландском, шведском.

\section{ЛИТЕРАТУРА}

1. Валгина Н.С., Розенталь Д.э., Фомина М.И. Современный русский язык: Учебник / Под редакцией Н.С. Валгиной. - 6-е изд., перераб. и доп. - М.: Логос, $2002.528 \mathrm{C}$.

2. Булычева Е.А., Орлова А.И. 0 проблемных вопросах залоговых форм// Вестник УдГУ. Филологические науки. 2007. № 5. Вып.1. С. 177-180.

3. Некрасова И.М. Семантика и функции немецкого пассива: дис. ... канд. фил. наук. - Пермь, 2000. - 161 с.

4. Зиндер Л.Р., Строева Т.В. Историческая морфология немецкого языка. - Л.: Просвещение, 1968. - 262 с.

5. Адмони В.Г. Исторический синтаксис немецкого языка. - М.: Высшая школа, 1963. - 334 с.

6. Гухман М.М. Развитие залоговых противопоставлений в германских языках: опыт историко-типологического исследования родственных языков. - М.: Наука, 1964. - 294 c.

7. Гухман М.М. Готский язык. - М.: Либроком, 2018. - 296 с.

8. Шубик С.А. Категория залога и поле залоговости в немецком языке. Автореферат диссер.. докт. филолог. наук - Л., 1991. - 38 с.

9. Шубик С.А. Становление категории залога в немецком языке (на материале древневерхненемецкой письменности) // Проблемы функциональной грамматики: Категоризация семантики/ под ред. А.В. Бондарко. - СПб.: Наука, 2008. - С. 406-412.

10. Жукова Н.С. Глагольная подсистема немецкого языка в различные периоды его развития// Вестник ТГПУ. 2005. Вып. № 4 (48).С. 10-15.

11. Agricola E., Fleischer W. Die deutsche Sprache: kleine Enzyklopedie. - Leipzig:VEB Bibliographisches Institut, 1969. - S. 613.

12. Грамматические категории германских языков в антропоцентрической перспективе. Коллективная монография / Отв. ред. Д.Б. Никуличева. Ред. колл.: Н.С. Бабенко, В.А. Нуриев, В.И. Карпов, Е.Б. Кротова, Т.В. Топорова, Е.Б. Яковенко. М., Изд-во «Канцлер» 2017. - 286 с. 